\title{
Validation of a new spectrometer for noninvasive measurement of cardiac output
}

\author{
Marc M. Baum, ${ }^{a), b)}$ Sasi Kumar, and John A. Moss ${ }^{\text {a) }}$ \\ Department of Chemistry, Oak Crest Institute of Science, 2275 E. Foothill Boulevard, Pasadena, \\ California 91107 \\ Peter D. Wagner \\ Division of Physiology, School of Medicine, University of California, San Diego, 9500 Gilman Drive, \\ La Jolla, California 92093
}

(Received 16 December 2003; accepted 4 April 2004; published online 21 June 2004)

\begin{abstract}
Acetylene is a blood-soluble gas and for many years its uptake rate during rebreathing tests has been used to calculate the flow rate of blood through the lungs (normally equal to cardiac output) as well as the volume of lung tissue. A new, portable, noninvasive instrument for cardiac output determination using the acetylene uptake method is described. The analyzer relies on nondispersive IR absorption spectroscopy as its principle of operation and is configured for extractive (side-stream) sampling. The instrument affords exceptionally fast $(30 \mathrm{~ms}, 10 \%-90 \%, 90 \%-10 \%$, at $500 \mathrm{~mL} \mathrm{~min}^{-1}$ flow rates), interference-free, simultaneous measurement of acetylene, sulfur hexafluoride (an insoluble reference gas used in the cardiac output calculation), and carbon dioxide (to determine alveolar ventilation), with good (typically $\pm 2 \%$ full-scale) signal-to-noise ratios. Comparison tests with a mass spectrometer using serially diluted calibration gas samples gave excellent $\left(R^{2}>0.99\right)$ correlation for all three gases, validating the IR system's linearity and accuracy. A similar level of agreement between the devices also was observed during human subject $\mathrm{C}_{2} \mathrm{H}_{2}$ uptake tests (at rest and under incremental levels of exercise), with the instruments sampling a common extracted gas stream. Cardiac output measurements by both instruments were statistically equivalent from rest to $90 \%$ of maximal oxygen consumption; the physiological validity of the measurements was confirmed by the expected linear relationship between cardiac output and oxygen consumption, with both the slope and intercept in the published range. These results indicate that the portable, low-cost, rugged prototype analyzer discussed here is suitable for measuring cardiac output noninvasively in a point-of-care setting. () 2004 American Institute of Physics.
\end{abstract}

[DOI: $10.1063 / 1.1764606$ ]

\section{INTRODUCTION}

The determination of cardiac output $\left(\dot{Q}_{T}\right)$-the amount of blood pumped by the heart per minute-at rest or during exercise is a powerful diagnostic tool for assessing both normal physiological function and patient health. Cardiac output represents in large part the body's ability to meet the metabolic demands of exercise. While, $\dot{Q}_{T}$ is routinely monitored in intensive care units, it is also an important diagnostic technique for cardiologists, physiologists, exercise physiologists, and researchers.

The conventional measures of $\dot{Q}_{T}$ are considered the direct Fick, dye dilution, and thermodilution methods. ${ }^{1}$ However, these techniques suffer from significant drawbacks, primarily resulting from their invasive nature; all three require cardiac and/or systemic arterial catheterization. Due to the serious nature of these interventions, and the associated risk, the techniques usually are restricted to monitoring hospitalized critically ill patients or in controlled laboratory settings.

A number of noninvasive measures of cardiac function

\footnotetext{
a) Also affiliated with the Division of Environmental Science and Engineering, California Institute of Technology, Pasadena, CA 91125.

b) Author to whom correspondence should be addressed; electronic mail: m.baum@oak-crest.org
}

have been developed to overcome the significant drawbacks of the above standard methods; the preferred technique is foreign gas uptake, as it meets all of the criteria of being noninvasive, simple to use, reliable over repeated measurements, accurate, and useful during exercise. ${ }^{1}$ The maneuver involves switching the subject to air containing trace amounts of a foreign, blood-soluble and a foreign, bloodinsoluble gas. Ventilation and partial pressures of these gases, along with that of carbon dioxide $\left(\mathrm{CO}_{2}\right)$, are measured continuously for $20-25$ breaths and used to determine $\dot{Q}_{T}{ }^{2,3}$ Foreign gas techniques are based on the fact that the inert, blood-soluble gas can enter the bloodstream only through the lungs. Both acetylene $\left(\mathrm{C}_{2} \mathrm{H}_{2}\right)$ and nitrous oxide $\left(\mathrm{N}_{2} \mathrm{O}\right)$ are widely used soluble gases, although many physiologists prefer to use $\mathrm{C}_{2} \mathrm{H}_{2},{ }^{4}$ as $\mathrm{N}_{2} \mathrm{O}$ is thought to be more significantly affected by blood lipid levels. ${ }^{5}$ The traditional approach has been to measure $\mathrm{C}_{2} \mathrm{H}_{2}$ uptake (washin) during rebreathing from a closed system, ${ }^{1,4,6-21}$ but a nonrebreathing (open-circuit) steady-state method also has been reported. ${ }^{2}$ Note that the $\mathrm{C}_{2} \mathrm{H}_{2}$ and $\mathrm{N}_{2} \mathrm{O}$ uptake methods measure pulmonary blood flow, which in healthy individuals equals $\dot{Q}_{T}$. In disease with pulmonary gas exchange inefficiency, these techniques measure "effective" pulmonary blood flow-a value less than actual $\dot{Q}_{T}$ that would be equal 
TABLE I. Performance specifications for a $\dot{Q}_{T}$ monitor using the foreign gas uptake method.

\section{Specification}

Simultaneous measurement of $\mathrm{C}_{2} \mathrm{H}_{2}, \mathrm{CO}_{2}$, and $\mathrm{SF}_{6}$ in a gaseous matrix Linear response

FS reading of $2.0 \% V \mathrm{C}_{2} \mathrm{H}_{2}, 0.25 \% V \mathrm{SF}_{6}$, and $10 \% V \mathrm{CO}_{2}$

Detection limits $(2 \sigma), 2 \%$ of FS or better for end-tidal and inspired

plateau averages

Accuracy, $\pm 2 \%$ of FS

Response time of $50 \mathrm{~ms}(10 \%-90 \%)$, or faster

No cross interferences between analytes

Insensitive to interferences from other breath components (e.g., $\mathrm{O}_{2}, \mathrm{~N}_{2}$, water vapor)

Low sample volume $\left(\sim 0.25 \mathrm{~cm}^{3}\right)$

Small (e.g., PC size), light $(<20 \mathrm{~kg})$ and rugged

Low power (e.g., $<25 \mathrm{~W}$ during steady state)

Ease of use

Low maintenance requirements

Suitable for telemetry

Analog and digital I/O to allow compatibility with off-the-shelf data acquisition systems

to $\dot{Q}_{T}$ in a virtual perfect lung having the same gas exchange performance as the actual diseased lung. While not the same as $\dot{Q}_{T}$, this value has functional significance and is itself useful. In addition to a blood-soluble gas, the foreign gas uptake method requires the measurement of an inert, bloodinsoluble gas-typically helium (He) or sulfur hexafluoride $\left(\mathrm{SF}_{6}\right)$ - to correct for incomplete gas mixing in the system, and as an indication of when gas mixing equilibrium in the lung is achieved. Exhaled $\mathrm{CO}_{2}$ concentrations are also needed to convert measured minute ventilation to alveolar ventilation.

Typical performance specifications for an instrument suitable for $\dot{Q}_{T}$ monitoring using the foreign gas method are listed in Table I. The technique requires rapid gas analysis, especially if measurements are to be made at high breathing frequencies during exercise. A fast response time is needed to accurately identify the inspired and end-expired concentrations for each breath. A response time of $\leqslant 50 \mathrm{~ms}$ is required for measurements during exercise.

The current instrument of choice for $\dot{Q}_{T}$ determination using the foreign gas method is the respiratory mass spectrometer (MS). Respired gas is sampled continuously from the subject's mouthpiece and introduced into the MS, where it is ionized and detected on a semicontinuous basis. Although this technique is fast with typical response times $(0 \%-90 \%)$ in the $50 \mathrm{~ms}$ range, it does possess some inherent limitations. The rebreathing MS is primarily a laboratory instrument, has high-power consumption, is bulky, experiences high sensitivity to mechanical vibration and shock, is complex to use, requires frequent calibration, and is expensive to purchase and maintain.

The work reported here describes a new instrument based on infrared (IR) absorption spectroscopy for measuring $\mathrm{C}_{2} \mathrm{H}_{2}, \mathrm{SF}_{6}$, and $\mathrm{CO}_{2}$ concentrations in breath, and hence $\dot{Q}_{T}$. The analyzer is compact, fast, has the potential of being significantly less expensive than a MS, and shows promise as a valuable clinical, field, and point-of-care device for monitoring $\dot{Q}_{T}$.

\section{SPECTROMETER}

\section{A. Infrared absorption spectroscopy of acetylene, sulfur hexafluoride, and carbon dioxide}

Acetylene, $\mathrm{SF}_{6}$, and $\mathrm{CO}_{2}$ have strong fundamental absorption bands in the IR portion of the electromagnetic spectrum, as shown in Fig. 1. This collection of bands is used as the basis for quantitative monitoring of these gases in breath by IR absorption spectroscopy. By controlling the sample temperature, pressure, and optical pathlength, the BeerLambert law can conveniently be applied to spectral data to calculate gas concentration. The technique has the potential benefits of meeting all the specifications listed in Table I. The gases can be measured directly without ionization (cf. mass spectrometry) or chemical transformation. A configuration affording extractive (side-stream) measurements-a small stream of the gas mixture is diverted and analyzed remotely from the subject-is discussed below.

\section{B. Optical layout and data acquisition}

The breath analysis spectrometer is shown schematically in Fig. 2. The IR source, a glowing coiled filament (SA10510-M, Cal-Sensors, Inc., Santa Rosa, CA) sealed under argon in a TO-8 package, is butt coupled to the sample cell, which consists of a light pipe with sapphire windows; the use of light pipes minimizes sample volume and, thus, maximizes instrument response time. ${ }^{22}$ The temperature of the sample cell is maintained above body temperature at $47^{\circ} \mathrm{C}$ to avoid condensation on the walls and optical windows during a breath analysis test. Radiation emerging from the cell is modulated at $900 \mathrm{~Hz}$ by an optomechanical chopper and collimated into the IR spectrometer by an off-axis parabolic reflector (A8037-176, Janos Technology, Inc., Townshend, VT). Data are acquired digitally by a miniature personal computer (PC) and software written in house. IR data are converted from analog to 16-bit digital values by the hardware at a frequency of $200 \mathrm{~Hz}$ and stored as ASCII files. The flowing gas sample is continuously delivered to the analyzer via $3.2 \mathrm{~mm}(0.125 \mathrm{in}$.) outer diameter perfluoroalkoxy tubing using a miniature dc pump; sample flow rates are measured by a digital flow sensor. Thus, the spectrometer is remote from the sampling point.

The IR spectrometer has been discussed in detail elsewhere. ${ }^{23}$ In summary, concentrations of the three gases of interest are measured by nondispersive IR absorption spectroscopy, ${ }^{24-26}$ using an innovative, modular optomechanical design; a water measurement channel was included in an earlier design. All analytes are measured in parallel and each has at least one dedicated detector-narrow bandpass optical filter (NBOF) pair. The NBOF isolates the spectral window where the measurement is made as shown in Fig. 1 for all analytes. The transmission maximum of the NBOF matches the absorption maximum of the analyte's spectral band. The spectral band is chosen on the basis of the absorption coefficient (line strength) and band position (i.e., minimize spectral interferences). Thus, the intensity of the photon flux at the sample detector is reduced in the presence of the corresponding analyte, whereas the reference detector is unaffected. Acetylene is measured by gas filter correlation 


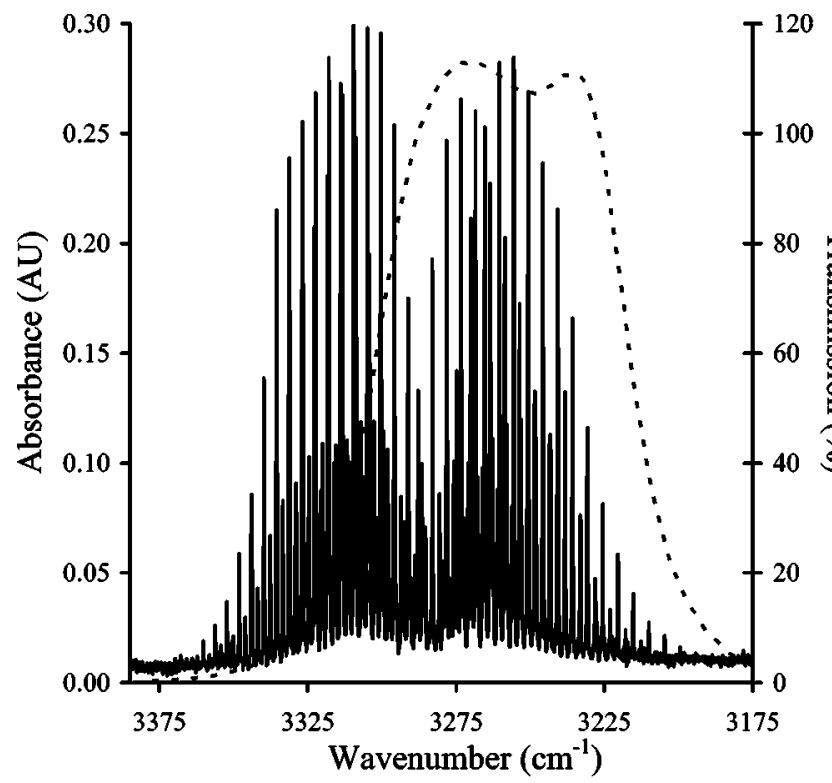

(a)

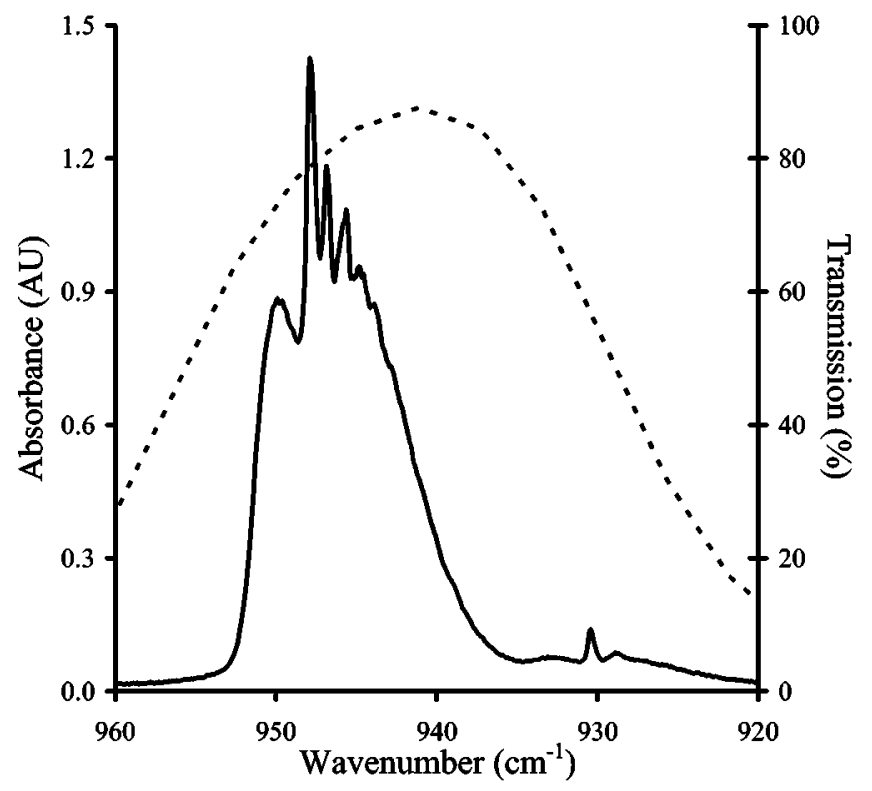

(b)

spectroscopy. ${ }^{24,26-34}$ High-frequency analysis of $\mathrm{SF}_{6}$ in the far-IR represented one of the key challenges in developing the prototype sensor. This difficulty was overcome by combining recent breakthroughs in near-room-temperature (i.e., no liquid-nitrogen-cooling requirements) long-wavelength IR photovoltaic detector technology ${ }^{35-37}$ with a highly efficient optical design and high-speed signal processing electronics. ${ }^{23}$ The high $\mathrm{CO}_{2}$ concentrations in expired breath (typically $>5 \% \mathrm{~V}$ ) lead to optical saturation of the strong ${ }^{12} \mathrm{CO}_{2}$ band at $2350 \mathrm{~cm}^{-1}$, leading to a highly nonlinear instrument response. A far more linear relationship between $\mathrm{CO}_{2}$ concentration and sample detector counts is obtained when using $P$ branch of the less abundant ${ }^{13} \mathrm{CO}_{2}$ isotope (typically 1\%), as shown in Fig. 1(c). ${ }^{38,39}$ This approach assumes a fixed isotopic ${ }^{13} \mathrm{CO}_{2} /{ }^{12} \mathrm{CO}_{2}$ ratio in breath, which is valid within the precision of the measurements.

The instrument is calibrated and evaluated in the labora-

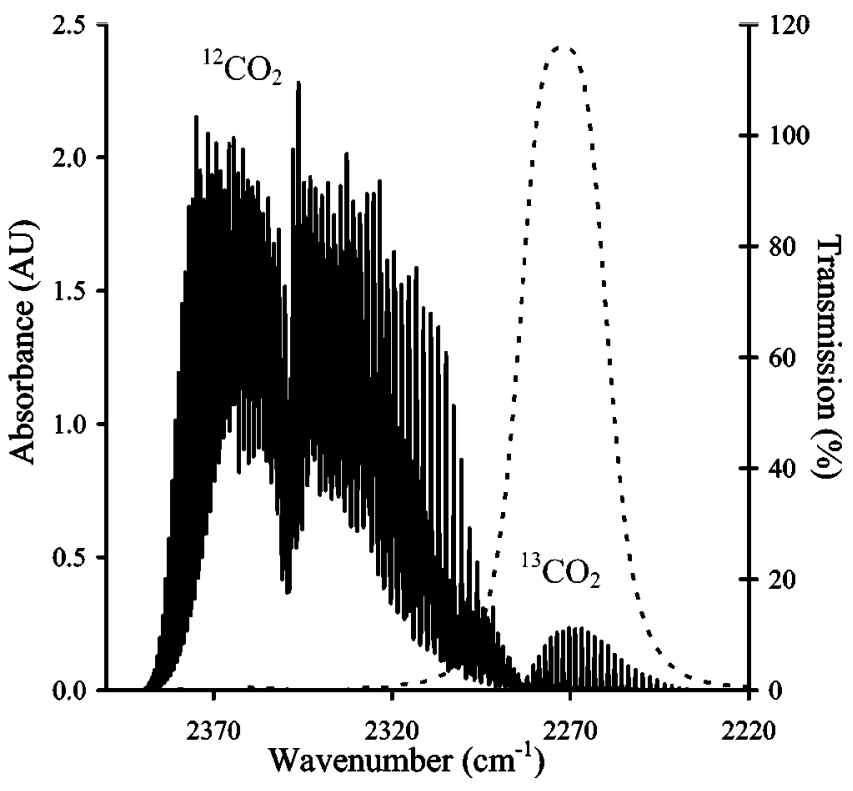

(c)

FIG. 1. (a) IR absorption spectrum of $493 \mathrm{ppm} \mathrm{m} \mathrm{C}_{2} \mathrm{H}_{2}$ (solid line) and transmission spectrum of $\mathrm{C}_{2} \mathrm{H}_{2} \mathrm{NBOF}$ (dotted line). (b) IR absorption spectrum of $58 \mathrm{ppm} \mathrm{m} \mathrm{SF}$ (solid line) and transmission spectrum of $\mathrm{SF}_{6} \mathrm{NBOF}$

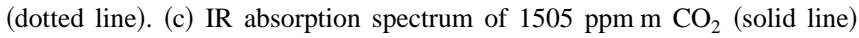
and transmission spectrum of $\mathrm{CO}_{2} \mathrm{NBOF}$ (dotted line). tory by connecting the sample cell to a gas manifold system. Synthetic mixtures of known concentration are prepared by blending certified gases using mass flow controllers. The exhaust from the blending system is flowed through the sample

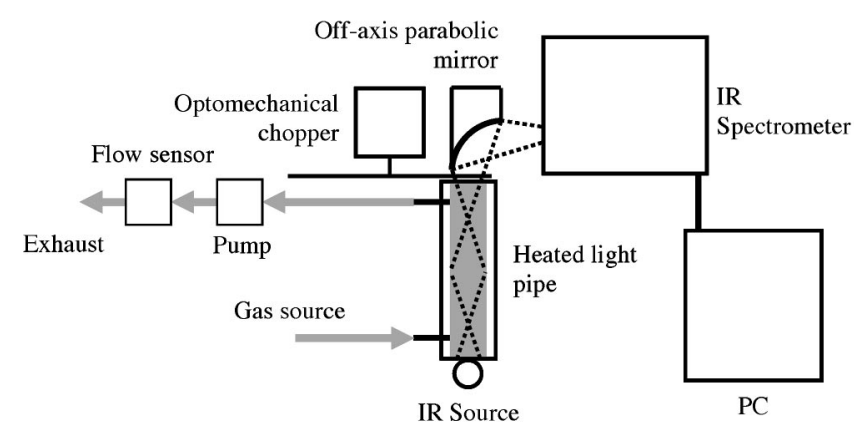

FIG. 2. Schematic representation of the IR breath gas analyzer. 


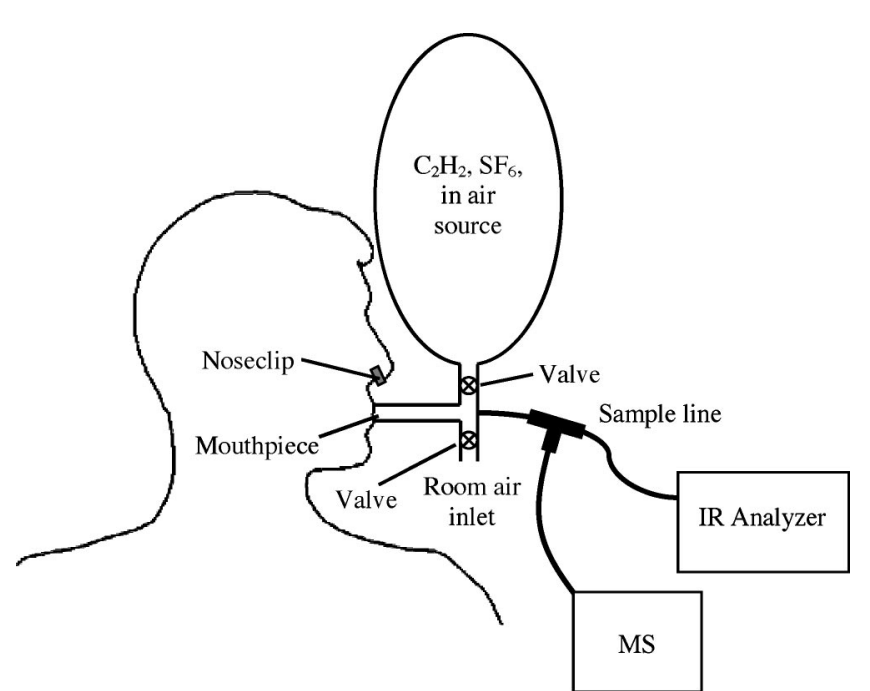

FIG. 3. Experimental configuration used in the human subjects studies.

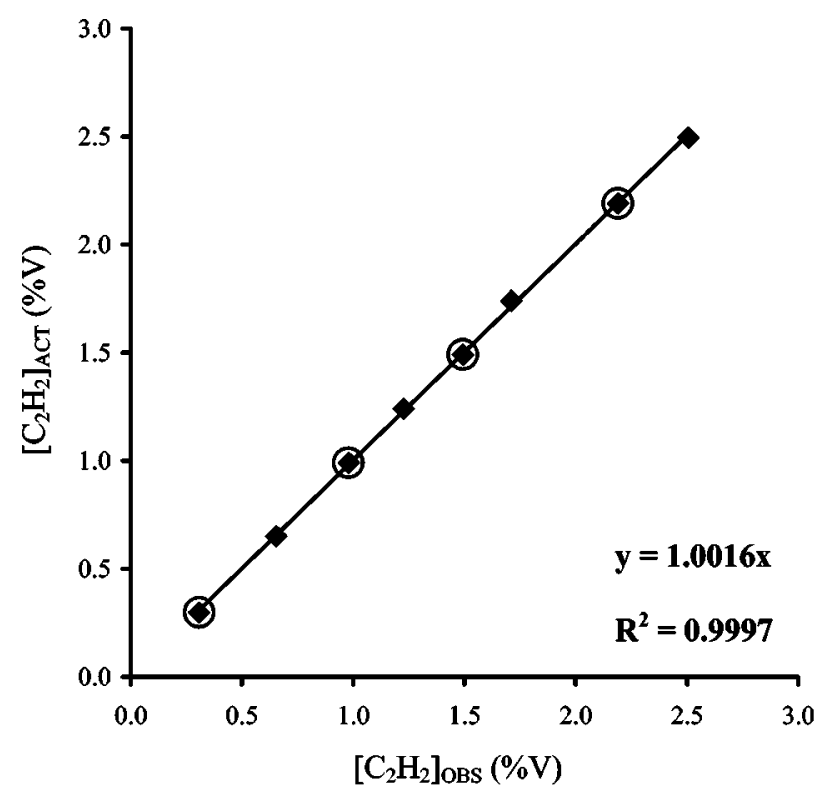

(a)

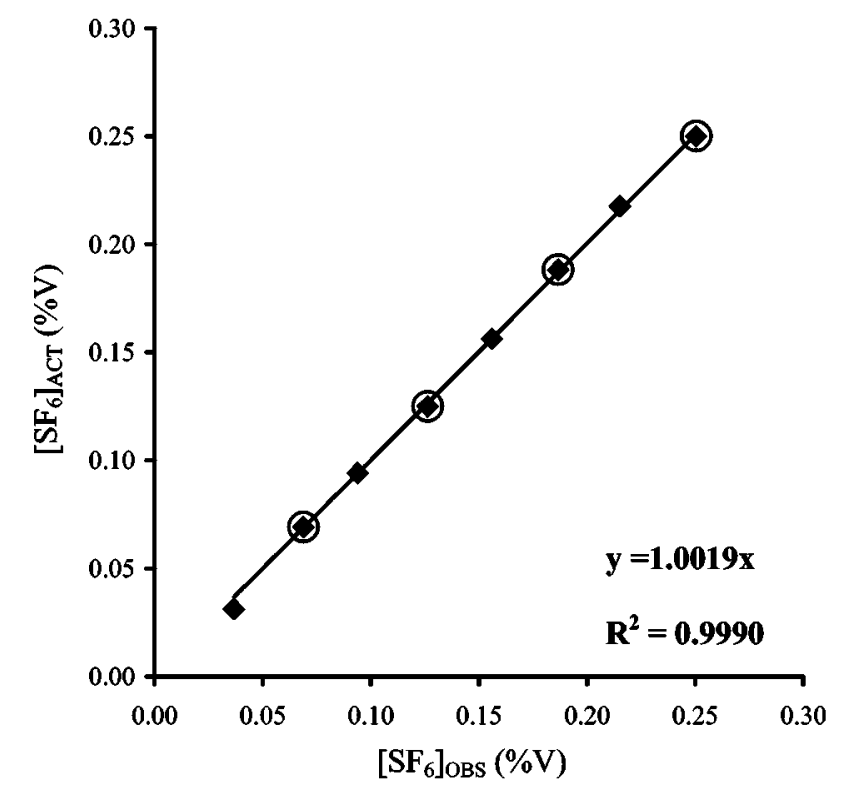

cell at $2 \mathrm{~L} \mathrm{~min}^{-1}$. The concentrations of the calibration mixtures are chosen to span the measurement range at equal intervals; four to five concentrations are used in a typical run. A plot of the known concentration of the calibration sample (actual concentration) versus the change in transmission relative to zero gas $(\Delta S R$, the difference between the signal ratios of the sample detector to the reference detector in the absence and in the presence of the analyte $)^{23}$ yielded a polynomial calibration curve that converted the analyzer response to linear concentration reading spanning the dynamic range. Response time measurements (10\%-90\% and 90\%-10\%) were carried out using a pair of rapid response $(<5 \mathrm{~ms}$ reaction time), low dead-volume ( $87 \mu \mathrm{L})$, three-way isolation valves (Series 100T, Bio-Chem Valve, Inc., Boonton, NJ) to successively direct either zero gas $\left(\mathrm{N}_{2}\right)$ or analyte gas to the measurement cell at a known flow rate.

Instrument correlation tests were carried out by channel-

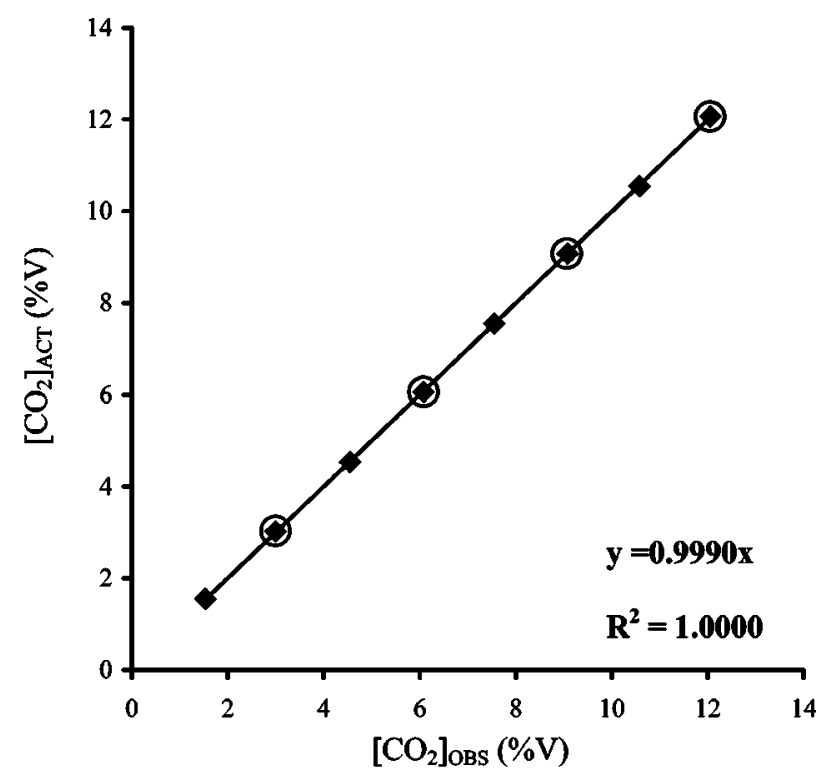

(c)

FIG. 4. (a) Acetylene linearity and accuracy validation; circled points were concentrations used in the calibration; ACT, actual (i.e., gas blend concentration); OBS, observed (i.e., measured by IR spectrometer). (b) Sulfur hexafluoride linearity and accuracy validation; circled points were concentrations used in the calibration. (c) Carbon dioxide linearity and accuracy validation; circled points correspond to gas blends used in the calibration.

(b) 


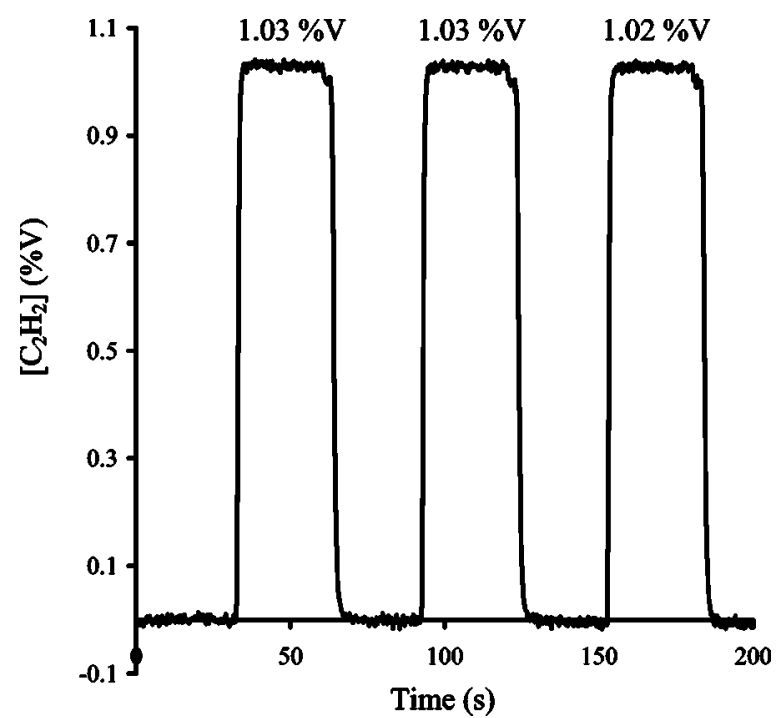

FIG. 5. Acetylene repeatability data with average measured values shown for each run.

ing a split gas stream from a common reservoir $(50 \mathrm{~mL}$ gastight syringe) containing an authentic mixture of $\mathrm{C}_{2} \mathrm{H}_{2}, \mathrm{SF}_{6}$, and $\mathrm{CO}_{2}$ in air to a magnetic sector MS (Model 1100, Perkin-Elmer, Pomona, CA) and the prototype IR analyzer. The response from both systems was recorded and compared.

Human subject tests were carried out on a healthy subject at rest and at three levels of exercise $(60,120$, and 180 $\mathrm{W})$. The subject had no prior history of respiratory or cardiac disease. After the subject gave written informed consent, a history was obtained, and a physical examination was performed to exclude cardiopulmonary abnormality. The subject then was screened for pulmonary disease with standard pulmonary function tests. The study was approved by the Human Subjects Committee of the University of California, San Diego, and by the U.S. Army Medical Research Acquisition Activity.

The nonrebreathing (open-circuit) method was used to measure $\dot{Q}_{T}$; the technique has been described in detail elsewhere. ${ }^{2}$ The subject rode on an electronically braked cycle ergometer (Excaliber, Quinton Instruments, Gronigen, Netherlands) at several workloads, with a noseclip, and breathed through a mouthpiece connected to a three-way valve coupled to a reservoir bag containing a $\mathrm{C}_{2} \mathrm{H}_{2}-\mathrm{SF}_{6}$-air blend with $\mathrm{C}_{2} \mathrm{H}_{2}$ concentrations below $2 \% \mathrm{~V}$ and $\mathrm{SF}_{6}$ concentrations below $0.3 \% \mathrm{~V}$ (Fig. 3). Room air was breathed through the sampling system for approximately 1 min prior to turning the valves to the $\mathrm{C}_{2} \mathrm{H}_{2}-\mathrm{SF}_{6}$-air source mixture to establish baseline values for each gas. The subject's breathing rate during these tests was $\sim 10 \mathrm{~min}^{-1}$ at rest and 31 $\mathrm{min}^{-1}$ at $180 \mathrm{~W}$ as part of a $120 \mathrm{~s}$ (or 20 breath) protocol. A gas stream was continuously aspired from the mouthpiece. A tee fitting split the gas flow between the MS and the prototype sensor, allowing their simultaneous comparison. Sample gas flow rates at the IR spectrometer were $630 \mathrm{~mL} \mathrm{~min}^{-1}$. Analog signals from the MS were digitized and logged at 20 $\mathrm{Hz}$ in a 12-bit data acquisition system in parallel with the IR spectrometer measurements, which were logged once every

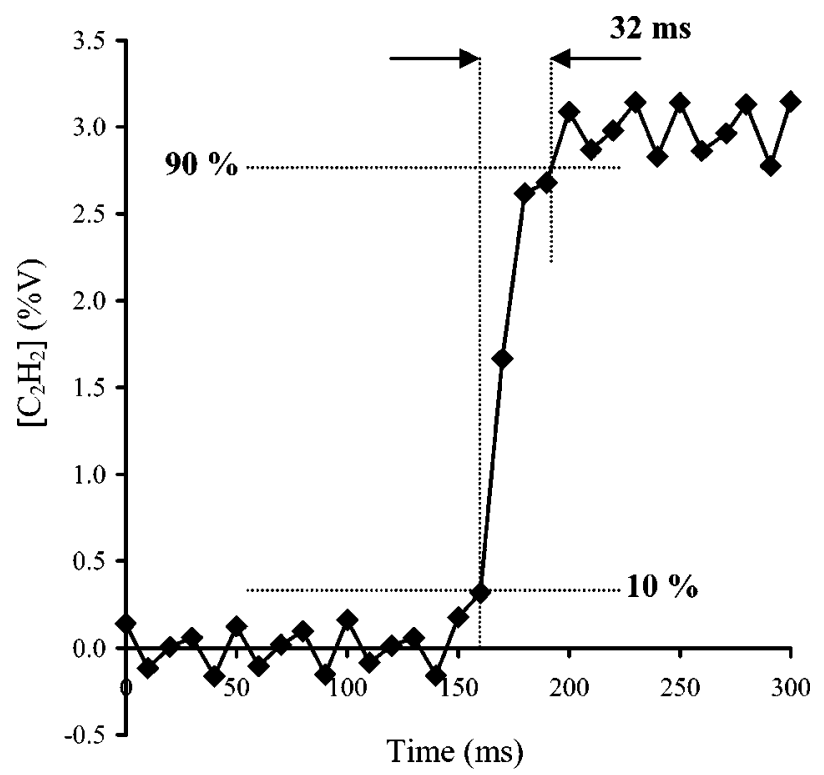

(a)

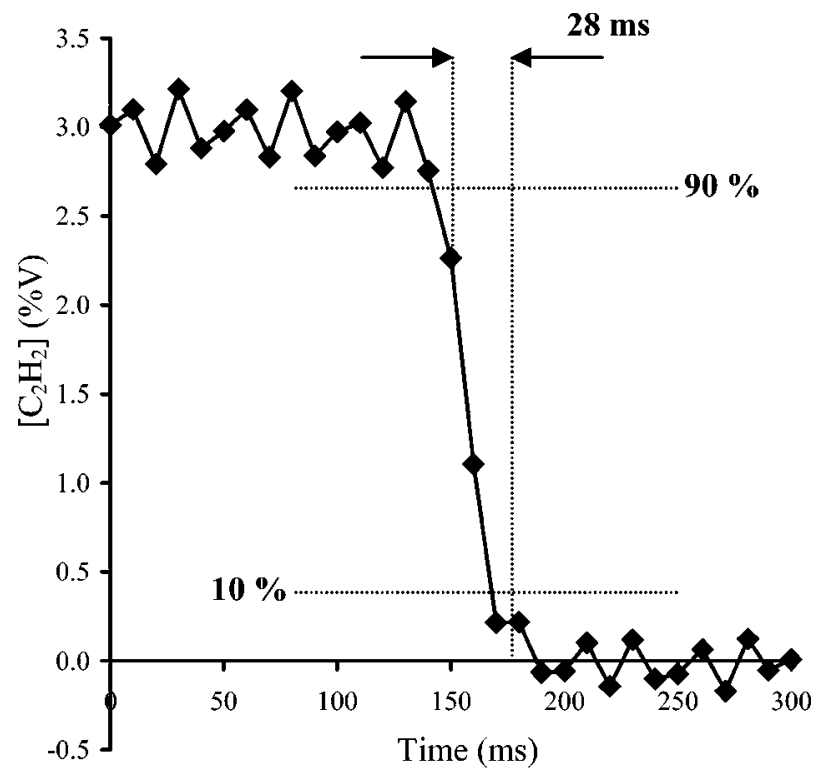

(b)

FIG. 6. (a) On-response time $(10 \%-90 \%)$ of the breath gas analyzer. (b) Off-response time $(90 \%-10 \%)$ of the breath gas analyzer.

$10 \mathrm{~ms}(100 \mathrm{~Hz})$. Expired gas flow and $\mathrm{O}_{2}$ consumption $\left(\dot{V} \mathrm{O}_{2}\right)$ was measured using an oxygen $\left(\mathrm{O}_{2}\right)$ uptake system (Consentius Tech, Salt Lake City, UT). Heart rate was monitored by EKG (Lifepak 6, Physio-control, Redmond, WA).

\section{LABORATORY TESTS}

\section{A. Calibration and performance evaluation}

Calibration of the IR analyzer (i.e., gas concentration as a function of $\Delta S R$ ) with known gas mixtures generally resulted in linear or quadratic plots for $\mathrm{C}_{2} \mathrm{H}_{2}$ and $\mathrm{CO}_{2}$, while $\mathrm{SF}_{6}$ calibration curves typically were third-order polynomials. Linearity and accuracy of the calibrated instrument were evaluated using eight gas mixtures per analyte; four concentrations were used in the calibration, four were not. The re- 
sults are shown in Fig. 4 and illustrate the calibrated instrument's high linearity and accuracy. The target accuracy specification of $\pm 2 \%$ of full-scale (FS) reading was exceeded by a factor of 4 in most cases. Instrument repeatability is shown in terms of $\mathrm{C}_{2} \mathrm{H}_{2}( \pm 0.5 \% \mathrm{FS}$; target specification: $\pm 2 \%$ FS) in Fig. 5. Note that the employed gas blend $\left(1.00 \% V \mathrm{C}_{2} \mathrm{H}_{2}\right.$ in $\mathrm{N}_{2}$ ) was not used in the instrument calibration. Thus, Fig. 5 provides both accuracy and repeatability information. A similar response was observed with $\mathrm{SF}_{6}$ and $\mathrm{CO}_{2}$ gas samples.

For an instrument to provide useful data, its measurements must be free of interferences from other matrix components typically present in breath. This is the case for the $\mathrm{SF}_{6}$ and $\mathrm{CO}_{2}$ channels, but the $\mathrm{C}_{2} \mathrm{H}_{2}$ fundamental $\nu_{3}\left(\sigma_{u}^{+}\right)$ parallel band ${ }^{40}$ at $3287 \mathrm{~cm}^{-1}$ [Fig. 1(a)] suffers from significant water interference, complicating $\mathrm{C}_{2} \mathrm{H}_{2}$ measurement in breath. This effect is more pronounced for the $\mathrm{C}_{2} \mathrm{H}_{2} R$ branch (higher energy), which is why a NBOF was chosen that overlaps with the $P$ branch. In addition, gas filter correlation spectroscopy was employed to further minimize any water interferences. Our approach to the elimination of water interference was evaluated by successively passing dry molecular nitrogen $\left(\mathrm{N}_{2}\right)$ and $\mathrm{N}_{2}$ saturated with water vapor at $40{ }^{\circ} \mathrm{C}$ through the sample cell and recording the $\mathrm{C}_{2} \mathrm{H}_{2}$ signal. No effect was observed. This lack of any water interference on $\mathrm{C}_{2} \mathrm{H}_{2}$ measurements was supported further by the flat baseline observed in all open-circuit uptake tests (vide infra) with the subject breathing room air. No cross interferences from the measured analytes were observed over the employed ranges, nor were any other interferences from significant breath gases.

\section{B. Response time determination}

The response time of side-stream devices has two components: (1) The time taken for the sample to transit the tubing from the mouthpiece to the sample cell (transit time); and (2) the time taken for the instrument to respond to changes in analyte concentration in the sample cell (rise time). Transit times were not recorded since only relative time information is of importance in our studies (i.e., temporal offsets in the experiment are irrelevant as long as all data are affected equally). For the purposes of this article, response time is discussed in terms of rise time. Fast instrument response to changing breath gas concentrations is critical for accurate determination of $\dot{Q}_{T}$, especially under exercise; it is generally accepted among physiologists that a response time of $50 \mathrm{~ms}(10 \%-90 \%)$, or faster, is required. Analyzer response times $(10 \%-90 \%, 90 \%-10 \%)$ of $30 \mathrm{~ms}$ were measured at sample flow rates of $500 \mathrm{~mL} \mathrm{~min}^{-1}$ (see Fig. 6 for $\mathrm{C}_{2} \mathrm{H}_{2}$ ). This is faster than the $50 \mathrm{~ms}$ typical of rebreathing MS's and four times faster than the most rapidresponding spectroscopic gas analyzer used in $\dot{Q}_{T}$ monitoring by the foreign gas method. The fast response time of the system described here is sufficient to provide accurate determination of inspired and end-tidal gas concentrations and, hence, $\dot{Q}_{T}$, even under heavy exercise, given respiratory frequencies that are usually $30-40 \mathrm{~min}^{-1}$ during exercise.

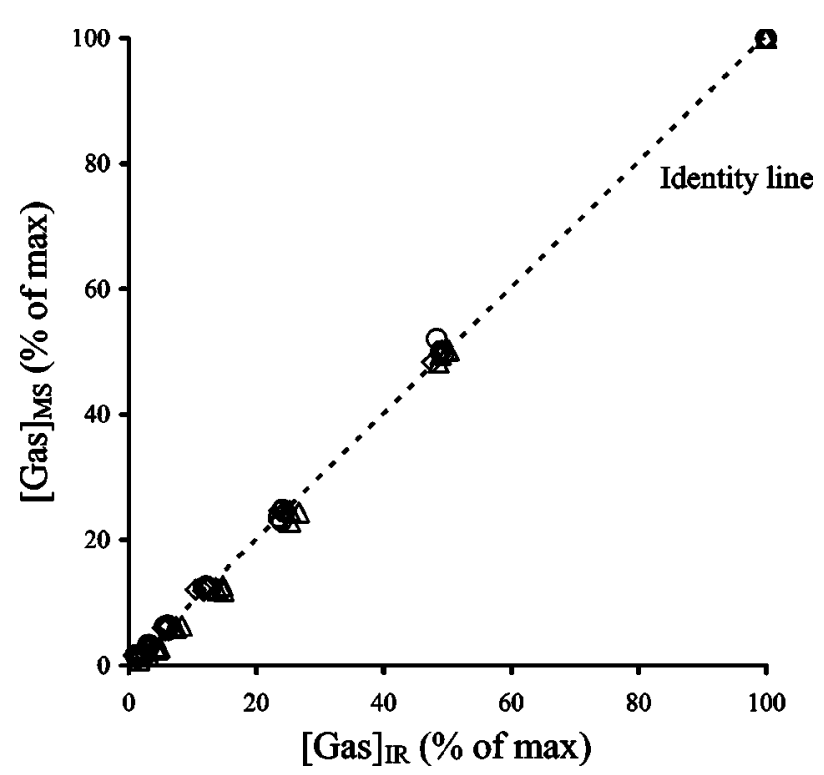

FIG. 7. Identity plot comparing readings from the respiratory MS, $[\mathrm{Gas}]_{\mathrm{MS}}$, and the IR analyzer, $[\mathrm{Gas}]_{\mathrm{IR}}$, as a function of gas mix concentration (diamonds: $\mathrm{C}_{2} \mathrm{H}_{2}$; triangles: $\mathrm{SF}_{6}$; circles: $\mathrm{CO}_{2}$ ).

\section{Data synchronization}

Aside from the need for fast instrument response times, the three measurement channels must also be synchronized. This prerequisite led us to employ separate detectors for parallel monitoring of each analyte. The degree of synchronization between the channels was evaluated by spiking a flowing stream of $\mathrm{N}_{2}$, sampled continuously by the analyzer, with synthetic gas mixtures containing $\mathrm{C}_{2} \mathrm{H}_{2}, \mathrm{SF}_{6}$, and $\mathrm{CO}_{2}$ in $\mathrm{N}_{2}$. These experiments showed that the channels were synchronized to better than $10 \mathrm{~ms}$, the highest temporal resolution of the system.

\section{Instrument correlation studies}

Results from the correlation studies between the respiratory MS and the IR analyzer sampling from a common synthetic gas blend are presented in Fig. 7. The excellent agreement between these data (Table II) clearly validates the accuracy and linearity of the IR analyzer relative to the MS, a well-established standard.

\section{BREATH ANALYSIS TESTS}

Analyte concentration time series measured by the IR analyzer during a human subject $\mathrm{C}_{2} \mathrm{H}_{2}$ uptake test is presented in Fig. 8(a) (subject at rest). The employed measurement frequency was $100 \mathrm{~Hz}$ (10 ms integration period), with

TABLE II. Relationship—slope and residual sum of the squares-between IR and MS concentration measurements of serially diluted synthetic gas mixtures.

\begin{tabular}{cccc}
\hline \hline Gas (IR), $x$ axis & Gas (MS), $y$ axis & Slope & $R^{2}$ \\
\hline $\mathrm{C}_{2} \mathrm{H}_{2}$ & $\mathrm{C}_{2} \mathrm{H}_{2}$ & 1.0043 & 0.9996 \\
$\mathrm{CO}_{2}$ & $\mathrm{CO}_{2}$ & 1.0064 & 0.9992 \\
$\mathrm{SF}_{6}$ & $\mathrm{C}_{2} \mathrm{H}_{2}{ }^{a}$ & 0.9929 & 0.9979 \\
\hline \hline
\end{tabular}

${ }^{\mathrm{a}} \mathrm{MS} \mathrm{SF}_{6}$ measurements were unstable at the time these tests were performed. 


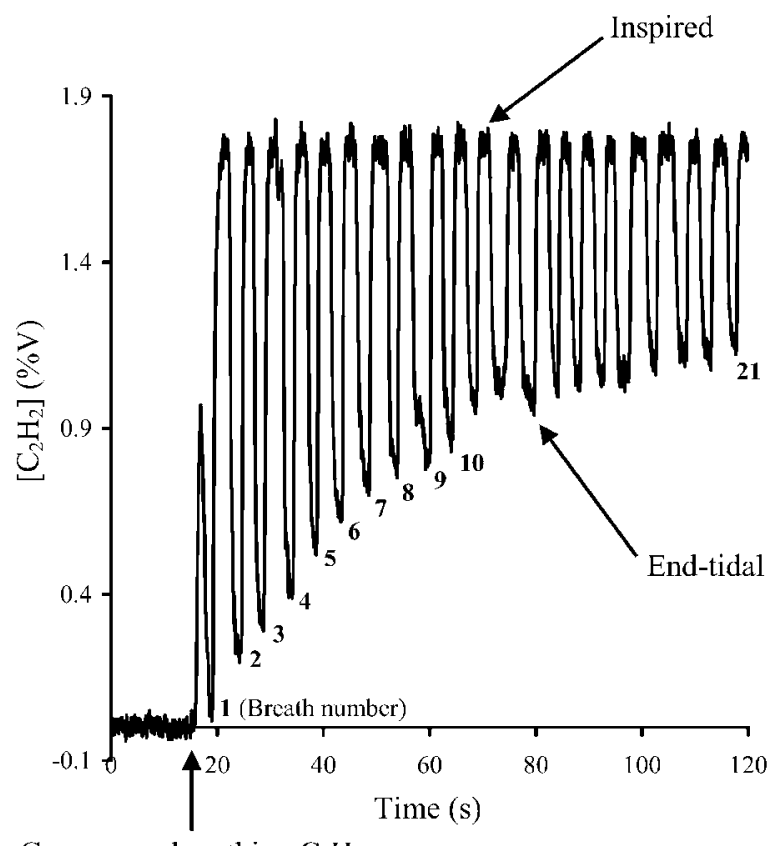

Commence breathing $\mathrm{C}_{2} \mathrm{H}_{2}$

(a)

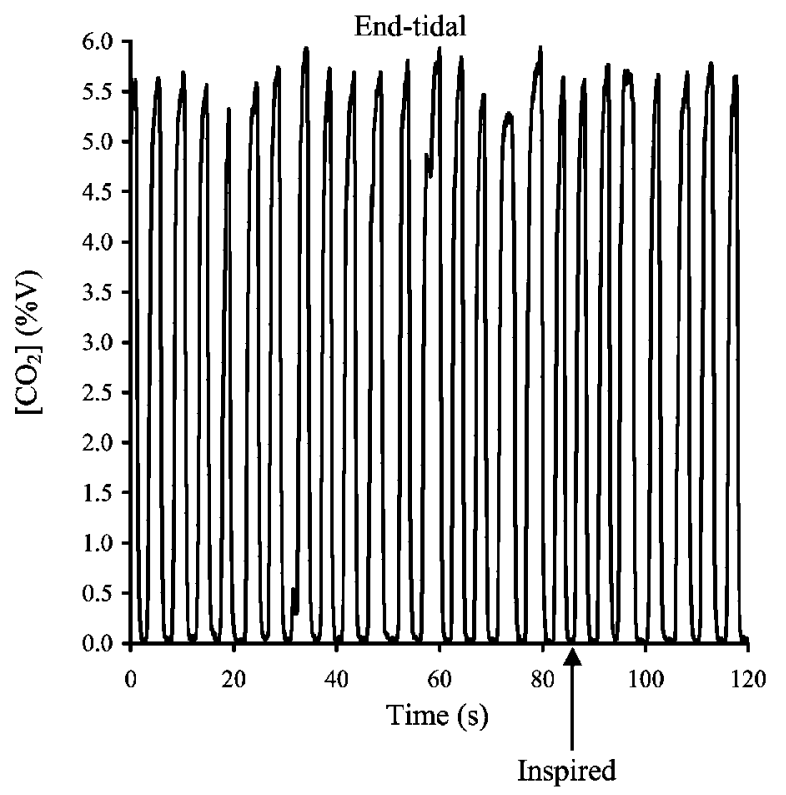

(c)

a rolling average of 12 digital samples (digital filtering is reduced for measurements under exercise). For $\mathrm{C}_{2} \mathrm{H}_{2}$, the baseline noise was $\pm 0.02 \% V \mathrm{C}_{2} \mathrm{H}_{2}$ affording a sensitivity $(2 \sigma)$ of $\pm 2 \%$ of $\mathrm{FS}$, assuming a $2 \% \mathrm{~V}$ measurement range. This is equivalent to typical specifications for commercial spectroscopic gas analyzers and comfortably meets the requirements for $\dot{Q}_{T}$ determination since multiple data points defining the end-tidal and inspired concentration plateaus are averaged into one quantity. Figure 8(b) shows the corresponding $\mathrm{SF}_{6}$ uptake curve. The signal-to-noise ratio of the readings decreases at high $\mathrm{SF}_{6}$ concentrations due to attenuation $(\sim 40 \%)$ of the light beam incident on the photodetector. However, the observed performance of the measurement channel combined with the employed signal processing regime (i.e., $\mathrm{C}_{2} \mathrm{H}_{2}$ data are employed to identify the range of

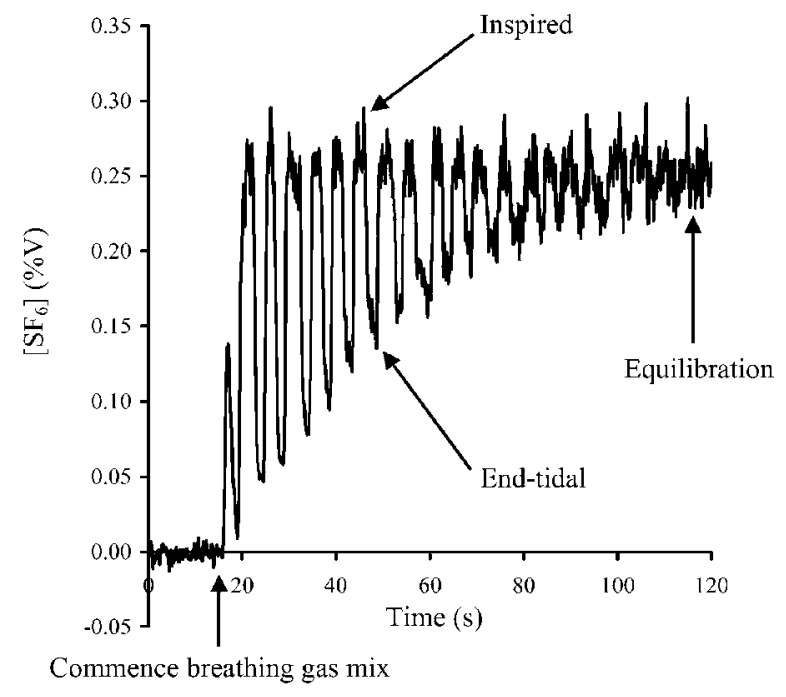

(b)

FIG. 8. (a) Acetylene uptake curve measured in a resting human subject by the IR analyzer showing the gradual rise of end-tidal $\mathrm{C}_{2} \mathrm{H}_{2}$ concentration during washin. (b) Sulfur hexafluoride concentration time series in a normal resting subject measured by the IR analyzer showing the gradual equilibration between the inspired gas mixture and the residual gas in the lungs. (c) Respired $\mathrm{CO}_{2}$ concentrations measured over 25 breaths by the IR analyzer during a $\mathrm{C}_{2} \mathrm{H}_{2}$ uptake study; end-tidal values remain essentially constant throughout.

$\mathrm{SF}_{6}$ data to average for each inspired and end-tidal value; this is possible due to the high level of temporal synchronization between the measurement channels) generated $\mathrm{SF}_{6}$ data within the required specifications for $\dot{Q}_{T}$ monitoring. Results from the human subjects tests discussed below further support the $\mathrm{SF}_{6}$ channel's ability to meet the desired performance specifications. Corresponding $\mathrm{CO}_{2}$ data from a human subject $\mathrm{C}_{2} \mathrm{H}_{2}$ uptake test are shown in Fig. 8(c). The observed noise associate with these measurements was less than $\pm 0.02 \% V \mathrm{CO}_{2}$ affording a sensitivity $(2 \sigma)$ of $\pm 0.4 \%$ $\mathrm{FS}$, assuming a $10 \% \mathrm{~V}$ measurement range, which significantly exceeds the performance requirements (Table I) without any further averaging.

Figure 9 shows the relationship between equilibrium 

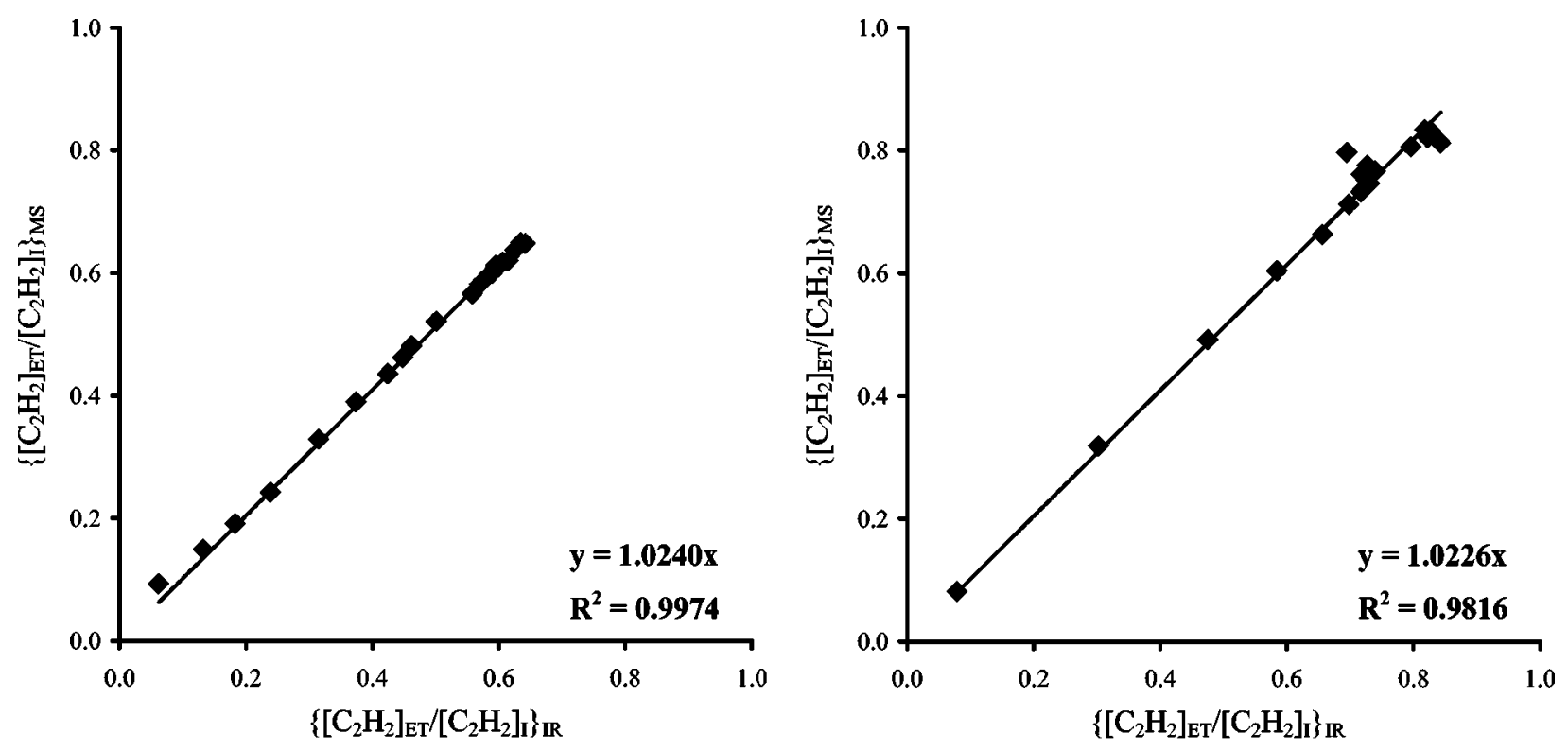

(a)

(c)
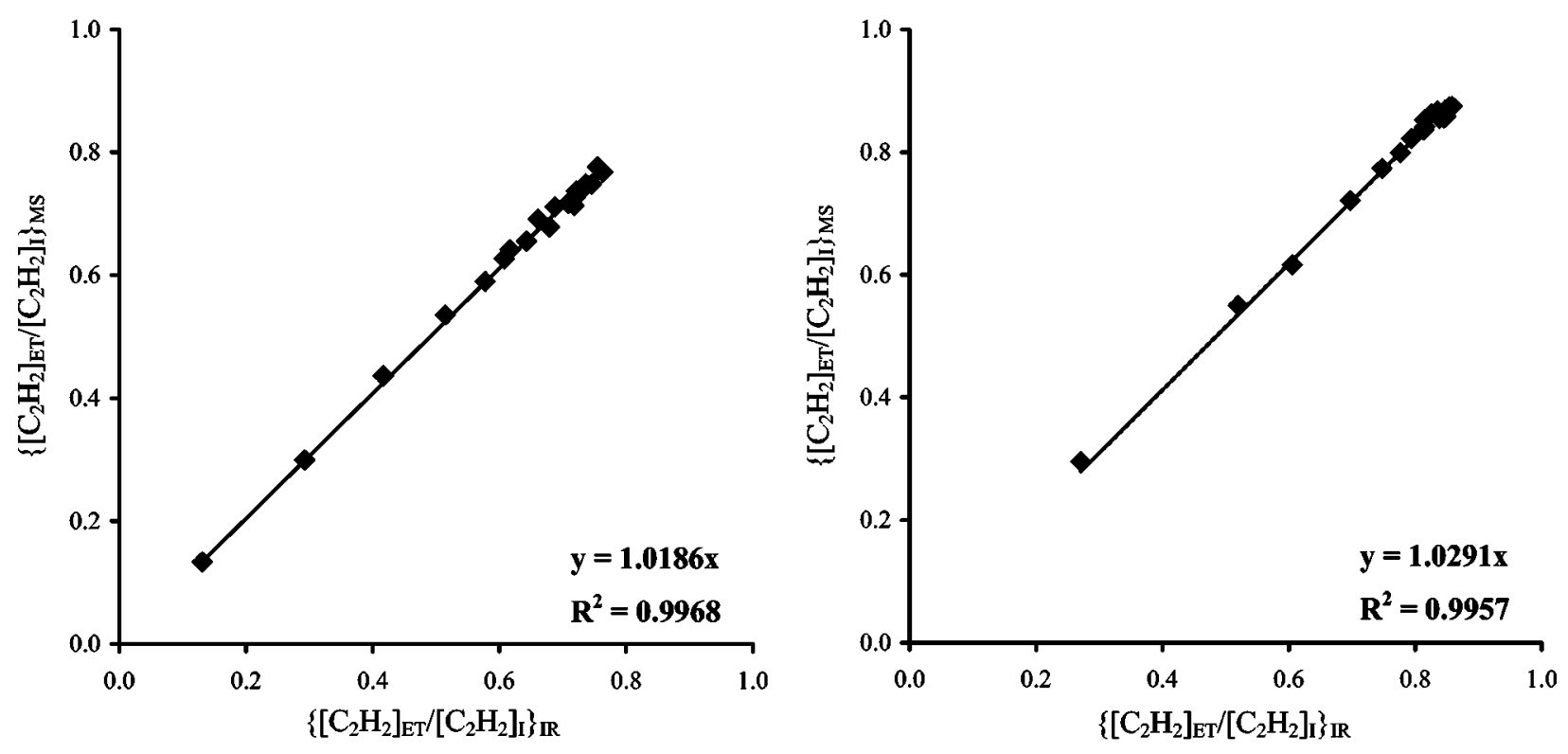

(d)

FIG. 9. (a) Comparison end-tidal (ET) to inspired (I) $\mathrm{C}_{2} \mathrm{H}_{2}$ concentration ratios, $\left[\mathrm{C}_{2} \mathrm{H}_{2}\right]_{\mathrm{ET}} /\left[\mathrm{C}_{2} \mathrm{H}_{2}\right]_{\mathrm{I}}$, measured in a resting, normal human subject by the IR analyzer and by the MS. (b) Comparison end-tidal (ET) to inspired (I) $\mathrm{C}_{2} \mathrm{H}_{2}$ concentration ratios, $\left[\mathrm{C}_{2} \mathrm{H}_{2}\right]_{\mathrm{ET}} /\left[\mathrm{C}_{2} \mathrm{H}_{2}\right]_{\mathrm{I}}$, measured in a normal human subject under $60 \mathrm{~W}$ of exercise by the IR analyzer and by the MS. (c) Comparison end-tidal (ET) to inspired (I) $\mathrm{C}_{2} \mathrm{H}_{2}$ concentration ratios, $\left[\mathrm{C}_{2} \mathrm{H}_{2}\right]_{\mathrm{ET}} /\left[\mathrm{C}_{2} \mathrm{H}_{2}\right]_{\mathrm{I}}$, measured in a normal human subject under $120 \mathrm{~W}$ of exercise by the IR analyzer and by the MS. (d) Comparison end-tidal (ET) to inspired (I) $\mathrm{C}_{2} \mathrm{H}_{2}$ concentration ratios, $\left[\mathrm{C}_{2} \mathrm{H}_{2}\right]_{\mathrm{ET}} /\left[\mathrm{C}_{2} \mathrm{H}_{2}\right]_{\mathrm{I}}$, measured in a normal human subject under $180 \mathrm{~W}$ of exercise by the IR analyzer and by the MS.

end-tidal and inspired $\mathrm{C}_{2} \mathrm{H}_{2}$ concentration ratios obtained with the IR analyzer and the MS, for the four open-circuit uptake tests (i.e., at rest and three incremental levels of exercise). There is excellent agreement (slope 1.023 \pm 0.004 , $R^{2}=0.993 \pm 0.008$ ) between the two instruments for all tests.

Figure 10 illustrates the excellent agreement between the MS and the IR analyzer in terms of $\dot{Q}_{T}$, determined from end-tidal and inspired gas concentrations of all three analytes using the method described by Barker et al. ${ }^{2}$ (previously validated by comparison with the established standard, the direct Fick method). Both instruments agree within the error limits of the method ( $\pm 10 \%$ of the reading), from rest to heavy exercise. The agreement between the instruments, as well as the physiological validity of the measurements, is further supported by Fig. 11. Not only are both instruments yielding statistically equivalent $\dot{Q}_{T}$ measurements, but these values also are symmetrically scattered about the predicted (based on $\dot{V} \mathrm{O}_{2}$ ) linear function using previous data from the direct Fick method. ${ }^{2}$

\section{DISCUSSION}

Although the inert gas rebreathing method for $\dot{Q}_{T}$ determination has been used extensively in basic cardiovascular research, the state of current technology has hampered widespread use of this established method in clinical, point-of- 


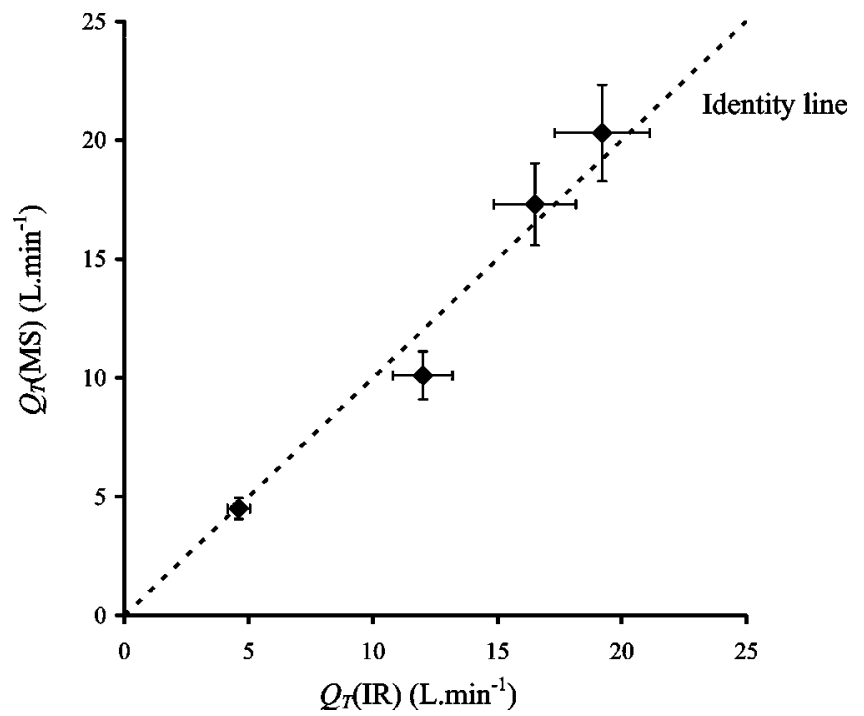

FIG. 10. Identity plot of MS and IR analyzer $\dot{Q}_{T}$ measurements from all four $\mathrm{C}_{2} \mathrm{H}_{2}$ uptake tests (rest, 60, 120, and $180 \mathrm{~W}$ ); error bars represent $\pm 10 \%$ of the reading.

care, and field-based applications. Portable IR spectrometers have been used to monitor $\mathrm{C}_{2} \mathrm{H}_{2}$ in breath, ${ }^{41}$ but the performance of these instruments is questionable, possibly due to poor control of the sample cell environment and water interferences. Clemensen et $a l^{42}$ employed a multicomponent $\left(\mathrm{O}_{2}, \mathrm{CO}_{2}\right.$, Freon 22 , and $\left.\mathrm{SF}_{6}\right)$ photoacoustic IR and paramagnetic (IR/PM) gas analyzer in inert gas-rebreathing and metabolic gas exchange measurements. The feasibility of replacing a conventional MS by such an instrument in a variety of noninvasive pulmonary gas exchange measurements was investigated for ten subjects at rest and during submaximal exercise. The IR/PM showed promise, although further

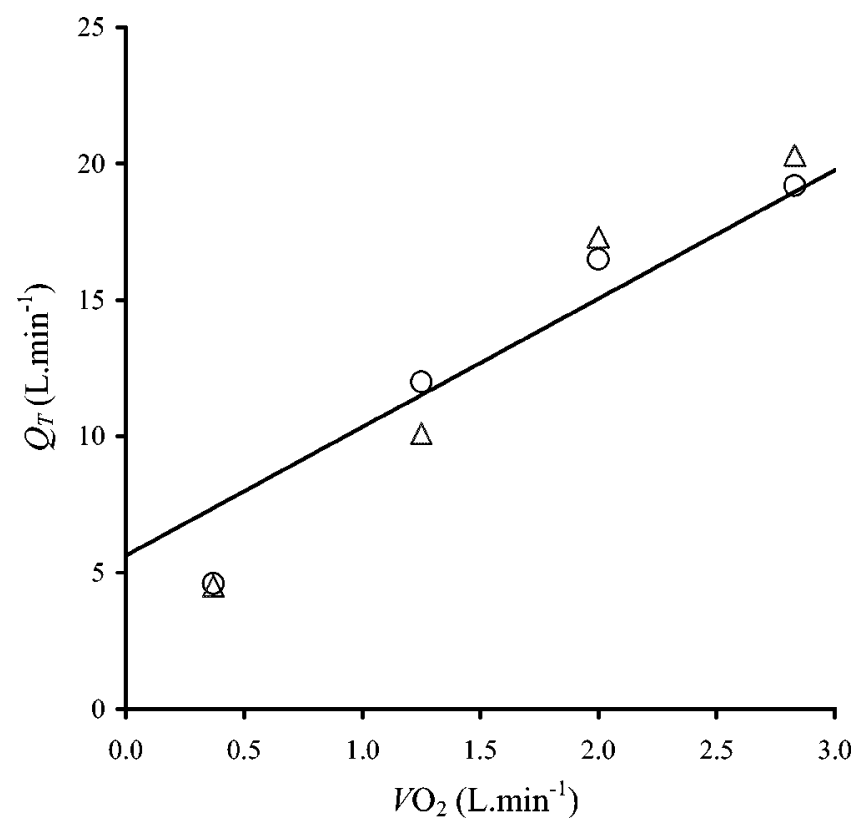

FIG. 11. Relationship between $\dot{Q}_{T}$ (triangles: MS; circles: IR) and $\mathrm{O}_{2}$ uptake $\left(\dot{V} \mathrm{O}_{2}\right)$ from all four $\mathrm{C}_{2} \mathrm{H}_{2}$ uptake tests (rest, 60, 120, and $180 \mathrm{~W}$ ); line denotes typical statistical relationship by direct Fick method $(\dot{Q}=4.71$ $\times \dot{V} \mathrm{O}_{2}+5.63$ ) (see Ref. 2). modifications to the instrument appeared to be required. More recently, the IR/PM technology was used to determine $\dot{Q}_{T}$ in heart failure patients and showed good agreement with measurements using the Fick and thermodilution methods. ${ }^{43}$ However, the system still had important practical drawbacks, including cost, the requirement for sample drying, and, most importantly, a slow response time $(10 \%-90 \%, 250 \mathrm{~ms}){ }^{42}$ The sampling frequency of $11 \mathrm{~Hz}(90 \mathrm{~ms})$ for one complete scan of all four gases establishes a fundamental limit to the system's response time, even at high gas flow rates. Broadband photoacoustic spectrometers (i.e., the technology platform used in the above systems) are known ${ }^{44}$ to often be limited by their selectivity. This is particularly relevant to the above $\mathrm{N}_{2} \mathrm{O}$ measurements, which have the potential for interferences by water (hence, the requirement for sample drying) and $\mathrm{CO}_{2}$.

We recently reported the use of dispersive ultraviolet (UV) spectroscopy for measuring $\mathrm{C}_{2} \mathrm{H}_{2}$ uptake and showed excellent agreement between our device and a MS in human subject studies. ${ }^{22}$ While this approach showed promise for $\dot{Q}_{T}$ monitoring, it would require bundling with separate measurement channels as the typical blood-insoluble gases and $\mathrm{CO}_{2}$ cannot be measured conveniently in the UV.

A new approach toward noninvasive $\dot{Q}_{T}$ monitoring using IR absorption spectroscopy is presented here. For the first time, this technique has been shown to provide accurate measures of $\dot{Q}_{T}$ at rest and under heavy exercise during rebreathing tests by human subjects.

Measurements of the key analytes required for $\dot{Q}_{T}$ determination by the prototype device - in the laboratory and during human subject open-circuit uptake tests-correlated exceptionally well with concurrent MS measurements. The prototype instrument is small, portable, and rugged, meeting the specifications shown in Table I. These results support the claim that a portable system measuring $\dot{Q}_{T}$ shows promise as a diagnostic field instrument for cardiovascular testing.

Current efforts in our laboratory are aimed at using this highly modular technology platform to add more measurement channels, including: $\mathrm{O}_{2}$ for metabolic function testing, and carbon monoxide $(\mathrm{CO})$ for pulmonary diffusing capacity of $\mathrm{CO}\left(D L_{\mathrm{CO}}\right)$ and pulmonary capillary blood volume determination using a steady-state method (i.e., multiple breaths) in parallel with $\dot{Q}_{T}$ monitoring in a single instrument.

\section{ACKNOWLEDGMENTS}

This research was carried out under the sponsorship of the National Medical Technology TestBed (NMTB) (Subagreement No. 2000-08-OCIofS-Baum). The authors gratefully acknowledge the valuable assistance provided by this program.

${ }^{1}$ D. E. R. Warburton, M. J. F. Haykowsky, H. A. Quinney, D. P. Humen, and K. K. Teo, Sports Med. 27, 23 (1999).

${ }^{2}$ R. C. Barker, S. R. Hopkins, N. Kellogg, I. M. Olfert, T. D. Brutsaert, T. P. Gavin, P. L. Entin, A. J. Rice, and P. D. Wagner, J. Appl. Physiol. 87, 1506 (1999).

${ }^{3}$ B. D. Johnson, K. C. Beck, D. N. Proctor, J. Miller, N. M. Dietz, and M. J. Joyner, J. Appl. Physiol. 88, 1650 (2000). 
${ }^{4}$ R. J. Smyth, N. Gledhill, A. B. Froese, and V. K. Jamnik, Med. Sci. Sports Exercise 16, 512 (1984).

${ }^{5}$ L. Cander and R. E. Forster, J. Appl. Physiol. 14, 541 (1959).

${ }^{6}$ M. Imamura, K. Ishida, T. Takagi, S. Torii, T. Nakamura, Y. Iwasaki, S. Yabuki, K. Machii, and K. Seki, Jpn. Circ. J. 48, 912 (1984).

${ }^{7}$ M. C. Kallay, R. J. Smith, R. W. Hyde, B. F. Schreiner, and R. L. Rothbard, Circulation 72, 188 (1985).

${ }^{8}$ R. O. Crapo, C. G. Elliott, and R. L. Jensen, Am. Rev. Respir. Dis. 133, A65 (1986).

${ }^{9}$ J. Nystrom, F. Celsing, P. Carlens, B. Ekblom, and P. Ring, Clin. Physiol. 6, 253 (1986).

${ }^{10}$ O. W. Nielsen, S. Hansen, P. Christensen, and J. Gronlund, Acta Anaesthesiol. Scand. 34, 354 (1990).

${ }^{11}$ H. Ochi, S. Morioka, S. Yano, T. Umeno, S. Naganuma, I. Ikuma, Y. Matsuno, S. Izumi, R. Murakami, and K. Moriyama, Am. J. Noninvas. Cardiol. 5, 106 (1991).

${ }^{12}$ O. W. Nielsen, S. Hansen, and J. Gronlund, J. Appl. Physiol. 76, 1560 (1994).

${ }^{13}$ C. C. W. Hsia, L. F. Herazo, M. Ramanathan, and R. L. Johnson, J. Appl. Physiol. 78, 1612 (1995).

${ }^{14}$ J. M. Steinacker, Y. Liu, D. Boning, A. Halder, N. Maassen, A. Thomas, and M. Stauch, Eur. J. Appl. Physiol. Occup. Physiol. 74, 187 (1996).

${ }^{15}$ S. Hansen, O. Wendelboe, and P. Christensen, Clin. Physiol. 17, 193 (1997).

${ }^{16}$ B. Krip, N. Gledhill, V. Jamnik, and D. Warburton, Med. Sci. Sports Exercise 29, 1469 (1997).

${ }^{17}$ Y. Liu, E. Menold, A. Dullenkopf, S. Reissnecker, W. Lormes, M. Lehmann, and J. M. Steinacker, Clin. Physiol. 17, 171 (1997).

${ }^{18}$ M. Rosenthal and A. Bush, Eur. Respir. J. 10, 2586 (1997).

${ }^{19}$ D. E. R. Warburton, N. Gledhill, and V. K. Jamnik, Med. Sci. Sports Exercise 30, 952 (1998).

${ }^{20}$ M. M. Hoeper, R. Maier, J. Tongers, J. Niedermeyer, J. M. Hohlfeld, M. Hamm, and H. Fabel, Am. J. Respir. Crit. Care Med. 160, 535 (1999).

${ }^{21}$ D. E. R. Warburton, M. J. F. Haykowsky, H. A. Quinney, D. P. Humen, and K. K. Teo, Sports Med. 27, 241 (1999).

${ }^{22}$ M. M. Baum, S. Kumar, A. M. Lappas, and P. D. Wagner, Rev. Sci. Instrum. 74, 3104 (2003).
${ }^{23}$ M. M. Baum and H. C. Lord, U.S. Patent No. 6,599,253, June 25, 2001.

${ }^{24}$ D. W. Egan, G. B. Holstrom, and H. C. Lord, U.S. Patent No. 3,837,744, Sept. 24, 1974.

${ }^{25}$ H. C. Lord, III, U.S. Patent No. 4,632,563, Dec. 30, 1986.

${ }^{26}$ P. L. Hanst and S. T. Hanst, in Air Monitoring by Spectroscopic Techniques, edited by M. W. Sigrist (Wiley, New York, 1994), Vol. 127, pp. $335-470$.

${ }^{27}$ R. Goody, J. Opt. Soc. Am. 58, 900 (1968).

${ }^{28}$ T. V. Ward and H. H. Zwick, Appl. Opt. 14, 2896 (1975).

${ }^{29}$ W. F. Herget, J. A. Jahnke, D. E. Burch, and D. A. Gryvnak, Appl. Opt. 15, 1222 (1976).

${ }^{30}$ H. A. Wallio, J. C. Casas, B. B. Gormsen, J. H. G. Reichle, and M. S. Saylor, Appl. Opt. 22, 749 (1983).

${ }^{31}$ H. S. Lee and H. H. Zwick, Rev. Sci. Instrum. 56, 1812 (1985).

${ }^{32}$ S. Cha and P. Gabele, Opt. Eng. 25, 1299 (1986).

${ }^{33}$ H. O. Edwards and J. P. Dakin, Sens. Actuators B 11, 9 (1993).

${ }^{34}$ J. P. Dakin, H. O. Edwards, and B. H. Weigl, Sens. Actuators B 29, 87 (1995).

${ }^{35}$ J. Piotrowski, W. Gawron, and Z. Djuric, Opt. Eng. 33, 1413 (1994).

${ }^{36}$ J. Piotrowski and W. Gawron, Infrared Phys. Technol. 36, 1045 (1995).

${ }^{37}$ J. Piotrowski and A. Rogalski, Sens. Actuators, A 67, 146 (1998).

${ }^{38}$ M. M. Baum, E. S. Kiyomiya, S. Kumar, A. M. Lappas, and H. C. Lord III, Environ. Sci. Technol. 34, 2851 (2000).

${ }^{39}$ M. M. Baum, E. S. Kiyomiya, S. Kumar, A. M. Lappas, and H. C. Lord III, Environ. Sci. Technol. 35, 3735 (2001).

${ }^{40}$ G. Herzberg, Infrared and Raman Spctra of Polyatomic Molecules (Van Nostrand-Reinhold, New York, 1945), Vol. 2.

${ }^{41}$ K. W. Barazanji, M. Ramanathan, R. L. Johnson, and C. C. W. Hsia, J. Appl. Physiol. 80, 1258 (1996).

${ }^{42}$ P. Clemensen, P. Christensen, P. Norsk, and J. Gronlund, J. Appl. Physiol. 76, 2832 (1994).

${ }^{43}$ A. Gabrielsen, R. Videbaek, M. Schou, M. Damgaard, J. Kastrup, and P. Norsk, Clin. Sci. 102, 247 (2002).

${ }^{44}$ M. W. Sigrist, in Air Monitoring by Spectroscopic Techniques, edited by M. W. Sigrist (Wiley, New York, 1994), Vol. 127, pp. 163-238. 